\title{
Minimally Invasive Posterior Decompression and Percutaneous Pedicle Screws Fixation for Thoracic Metastatic Tumor
}

\author{
Yu-Tong Gu*, Zhang L, Wang YC and Dong J
}

Department of Orthopaedic Surgery, Zhongshan Hospital, Fudan University, Shanghai, P.R. China

\begin{abstract}
Objectives: To evaluate the feasibility, efficacy and safety of percutaneous vertebroplasty (PVP), minimally invasive decompression and partial tumor resection combined with percutaneous pedicle screws fixation (PPS) for surgical treatment of thoracic metastasis with neurologic compression.

Methods: Twenty patients with 1-level thoracic vertebral metastasis and neurologic compression were treated with the procedure of PVP and PPS combined with minimally invasive neurologic decompression and partial tumor resection through mini posterior midline approach. The prognostic score was evaluated according to Tomita scoring system before operation. VAS score and ASIA grade were also recorded before and after operation. Cobb angles, central and anterior vertebral body height were measured on the lateral X-rays.

Results: The mean prognostic score of Tomita was 7 (range, 6-7 points). The mean follow-up of 13.8 (12-15) months was available for 17 patients and other 3 patients died more than half one year after operation. There were no complications and no death due to complications of the procedure itself. The VAS significantly dropped from 9 (range, $7-10)$ preoperatively to 3 (range, 2-4) $(p<0.001)$ immediately after surgery and to 1 (range, $0-1)(p<0.001)$ at the 1 -year follow-up. All patients got improvement of paraplegia after operation. At the 3-month follow-up, 3 of 5 patients with complete motor paralysis improved from ASIA scale $B$ to $D, 11$ of 15 patients with incomplete motor paralysis from $C$ or D to E. Eleven of 17 surviving patients got ASIA scale E at the 1-year follow-up. Spine stability was observed in all of the surviving patients during the follow-up.
\end{abstract}

Conclusion: PVP, minimally invasive decompression and partial tumor resection combined with PPS is a good choice of surgical treatment for thoracic metastatic tumors with neurologic compression.

Keywords: Spinal metastasis; Percutaneous vertebroplasty; Pedicle screw fixation; Neurological decompression; Minimally invasive spine surgery

\section{Introduction}

Medical progress has resulted in the increase of survival rates among cancer patients despite of an increase in metastatic lesions these years. Among the different tumors, bone metastasis is the second most common site of metastases, and there are secondary spine tumors in approximately $30 \%$ of cancers [1,2]. Spinal metastasis is a significant cause of morbidity due to pain, pathologic fracture, and neurologic compromise [3-6]. Axial loading of the vertebrae weakened by osteolytic metastases have an elevated risk of burst fracture through internal pressurization, which can cause bone and tumor tissue entering into the spinal canal [6,7]

Before pathologic fracture, pain is the most common symptom of metastatic tumor as a result of mechanical instability induced by the lytic destruction of spinal elements [8,9]. Multimodal non-operative interventions are used to treat spinal metastase including analgesia, corticosteroids, radiation therapy and chemotherapy [10]. These treatments provide pain relief, but do not get immediate biomechanical stability. Percutaneous vertebroplasty (PVP) is a minimally invasive, radiologically guided therapeutic procedure that is performed to inject the cement into the vertebral body for reducing pain and stabilizing structurally weakened vertebrae. Some reports showed that the analgesic efficacy of PVP was obtained in most patients of malignancies treated with PVP [11-16]. In addition, PVP can prevent further vertebral collapse and spinal cord compression $[17,18]$.

Only PVP is not regarded to be optimal for spinal metastatic tumor accompanied with symptoms of neurologic compression, as the procedure without decompression cannot improve neurological function [19]. The neurological decompression, spinal tumor resection and stabilization with instrumentation should be performed either from an anterior, posterior, or a combined approach [20,21]. Surgical options of spinal tumor resection include total en bloc spondylectomy (TES), vertebrectomy, sagittal resection, resection of the posterior arch, piecemeal excision, eggshell curettage, palliative surgery and so on [20,21]. However, these operations have significant morbidity related to the surgical approach, potential blood loss, extensive dissection or biomechanical instability due to the collapse of involved vertebra [22-24]. In this study PVP and percutaneous pedicle screws fixation (PPS) combined with minimally invasive neurological decompression and partial tumor resection through mini posterior midline approach were performed to treat thoracic metastasis with epidural involvement and neurologic symptoms for decreasing the aggressiveness, blood loss and preventing anterior column collapse and hardware failure. The feasibility, efficacy and safety of this method were evaluated.

\section{Materials and Methods}

\section{Population data}

The radiologic and clinical records of patients with 1-level thoracic vertebral metastasis and neurologic symptoms who underwent PVP, minimally invasive decompression and partial tumor resection

*Corresponding author: Yu-Tong Gu, Department of Orthopaedic Surgery, Zhongshan Hospital, Fudan University, Shanghai 200032, P.R. China, Tel: +8621-64041990-2907, 13816256848; E-mail: 447574313@qq.com

Received December 12, 2018; Accepted January 07, 2019; Published January 24, 2019

Citation: Gu YT, Zhang L, Wang YC, Dong J (2019) Minimally Invasive Posterior Decompression and Percutaneous Pedicle Screws Fixation for Thoracic Metastatic Tumor. J Spine 8: 431. doi: 10.4172/2165-7939.1000431

Copyright: ( 2019 Gu YT, et al. This is an open-access article distributed under the terms of the Creative Commons Attribution License, which permits unrestricted use, distribution, and reproduction in any medium, provided the original author and source are credited. 
combined with PPS in our hospital between December 2013 and June 2014 were retrospectively reviewed. Before the procedure, all patients gave informed consent, and our hospital review board did not require further approval for the use of patients' records and images.

One thoracic vertebral body lesion combined with neurologic compression and neurologic deficit was indication for PVP, minimally invasive decompression and partial tumor resection combined with PPS. Patients who underwent PVP for a malignant vertebral lesion without epidural involvement or for trauma, osteoporosis, or angioma were excluded from this study.

\section{Pre- and post-procedural imaging}

All patients were evaluated before the operation by CT and MRI imaging to quantify the degree of vertebral collapse and neurological compression. After the treatment, CT images were obtained to assess neurological decompression, position of pedicle screws, and extravertebral leakage of cement.

\section{Spine instability assessment}

The Spinal Instability Neoplastic Score (SINS) system [25,26] (Table 1), developed by the Spinal Oncology Study Group (SOSG), evaluates spinal stability by adding together six radiographic (location, bone lesion, radiographic spinal alignment, vertebral body collapse and posteriolateral involvement of spinal elements) and clinical (pain) components, with a score ranging from 0 to 18 . The total score is divided in three categories of stability: stable (0-6 points), potentially unstable (7-12 points), and unstable (13-18 points).

\section{Surgical procedure}

All surgeries were undertaken by the senior spine surgeon (YT

\begin{tabular}{|c|c|}
\hline Variables & Score \\
\hline \multicolumn{2}{|l|}{ Location } \\
\hline Junctional (occiput-C2, C7-T2, T11-L1, L5-S1) & 3 \\
\hline Mobile spine (C3-C6, L2-L4) & 2 \\
\hline Semirigid (T3-T10) & 1 \\
\hline Rigid (S2-S5) & 0 \\
\hline \multicolumn{2}{|l|}{ Pain $^{*}$} \\
\hline Yes & 3 \\
\hline Occasional pain but not mechanical & 1 \\
\hline Pain-free lesion & 0 \\
\hline \multicolumn{2}{|l|}{ Bone lesion } \\
\hline Lytic & 2 \\
\hline Mixed (lytic / blastic) & 1 \\
\hline Blastic & 0 \\
\hline \multicolumn{2}{|l|}{ Radiographic spinal alignment } \\
\hline Subluxation / translation present & 4 \\
\hline De novo deformity (kyphosis / scoliosis) & 2 \\
\hline Normal alignment & 0 \\
\hline \multicolumn{2}{|l|}{ Vertebral body collapse } \\
\hline$>50 \%$ collapse & 3 \\
\hline$<50 \%$ collapse & 2 \\
\hline No collapse with $>50 \%$ body involved & 1 \\
\hline None of the above & 0 \\
\hline \multicolumn{2}{|l|}{ Posterolateral involvement of spinal elements ${ }^{* *}$} \\
\hline Bilateral & 3 \\
\hline Unilateral & 1 \\
\hline None of the above & 0 \\
\hline
\end{tabular}

Table 1: SINS scoring system.
$\mathrm{Gu}$ ). The patients were operated in the prone position on a radiolucent table. PVP (Ruibang, Shanghai, China), minimally invasive decompression and partial tumor resection combined with PPS (Viper, Depuy Spine, and Raynham, Massachusetts, USA) were performed on all cases under general anesthesia. The involved vertebra was identified and the skin was marked under anteroposterior fluoroscopic control before the operation.

The first surgical stage consisted of performing PPS and PVP under fluoroscopic control. During PPS, the cannulated pedicle screws were placed into the adjacent 2-level vertebrae above and below the involved vertebrae through the pedicles. The entry point of instrumented pedicle was located at the lateral and middle margin of the pedicle image on the posteroanterior $\mathrm{C}$-arm view. The puncture needles of 13-gauge were inserted into the pedicles till the posterior wall of vertebrae on the lateral view, and the tips of needles should be close to the medial margin of pedicle image on the posteroanterior view. And then the needles were continuously advanced to the anterior central aspect of vertebrae under fluoroscopic guidance and adjusted parallel to the endplate on the lateral view. The guide wire was passed into vertebra through the needle and the dilation tubes were inserted over the guide wire through the 15 -mm skin incision to push the soft tissue away till the entry site of pedicle after removing the needle. The opener and thread tapping were used to enter the pedicle within the dilation tube. The cannulated pedicle screw of appropriate length was then introduced over the guide wire into the vertebral body via the pedicle. Two 13-gauge puncture needles were inserted into the metastatic vertebral body through the pedicles under fluoroscopic monitor. During PVP the cement (PMMA, Polymethylmethacrylate) was injected into the vertebral body until the cement approached the posterior aspect of the vertebral body or leaked into an extraosseous space. Two rods were contoured according to normal spine curve and placed over the pedicle screws through subcutaneous soft tissues (Figure 1).

In the second surgical phase, minimally invasive decompression and partial tumor resection were performed through small midline incision. The paraspinal sacrospinalis muscle was elevated subperiosteally to expose the spinal process and lamina, which were removed to expose the dural sac for neurologic decompression. Facetectomies and pedicle resection were performed to get the posterior part of vertebral body, and piecemeal resection of tumor were undertaken to create a cavity in the vertebral body. Then the curved dura dissector was carefully inserted into the interface between the tumor and dura to push forward the posterior tumor compressing neurologic elements into the cavity of vertebral body and make "separation" of spinal cord and tumor for complete decompression, a procedure termed partial tumor resection (Figure 2).

The patients were mobilized as soon as feasible after surgery and encouraged to resume their daily routine after leaving the hospital. Postoperative chemotherapy was offered to patients with good medical conditions and radiation therapy to 12 patients to prevent local recurrence of thoracic metastasis. Intensity-modulated radiotherapy was given to the operated level 2 weeks after surgery when the wound had healed. The total radiation dosage was usually $4000 \mathrm{cGy}$ and was administered over a 20 -day course in 4 weeks, with 200 cGy doses per day delivered in the first 5 days and then a break of 2 days during 1 week. 
Citation: Gu YT, Zhang L, Wang YC, Dong J (2019) Minimally Invasive Posterior Decompression and Percutaneous Pedicle Screws Fixation for Thoracic Metastatic Tumor. J Spine 8: 431. doi: 10.4172/2165-7939.1000431

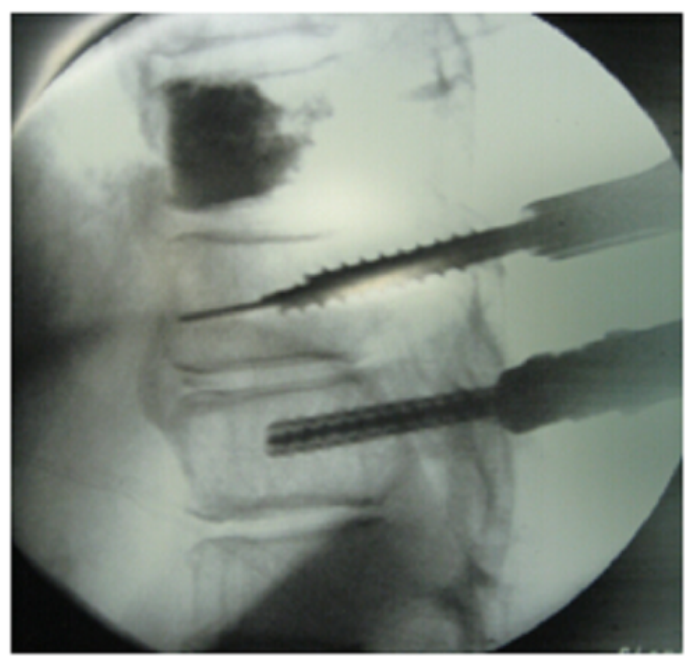

A

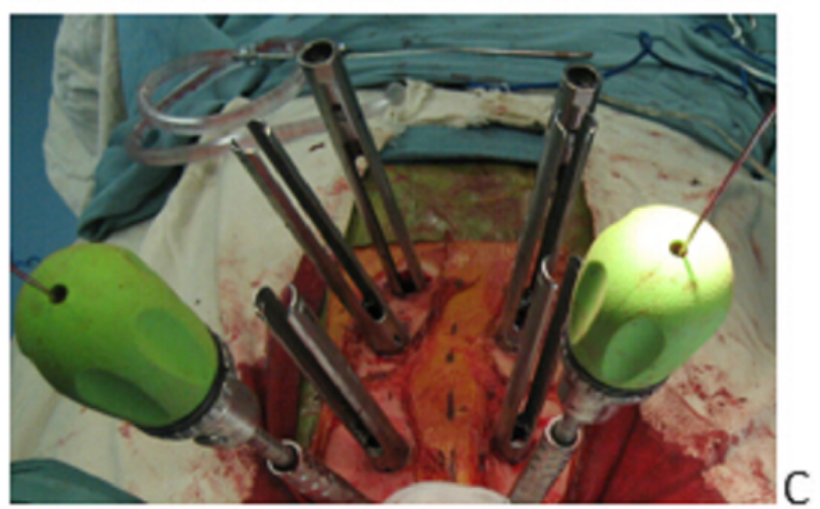

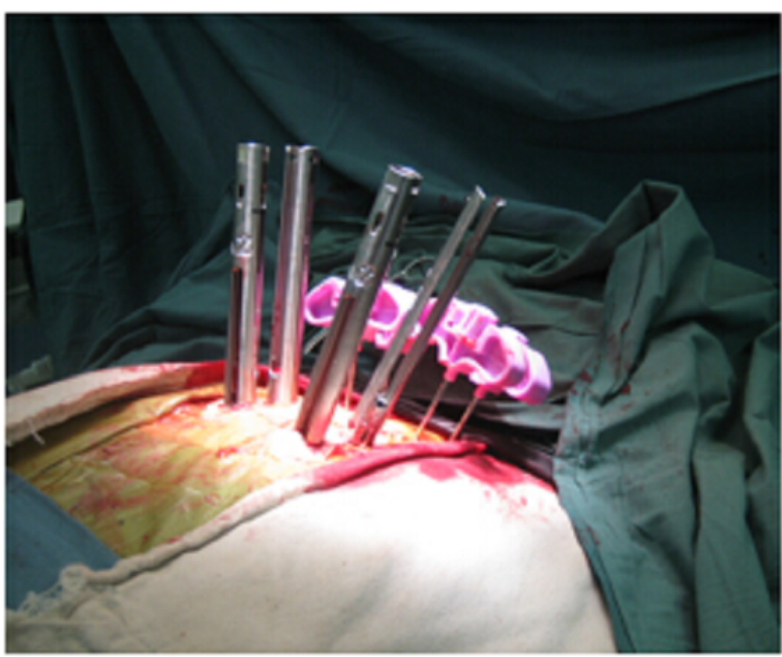

B

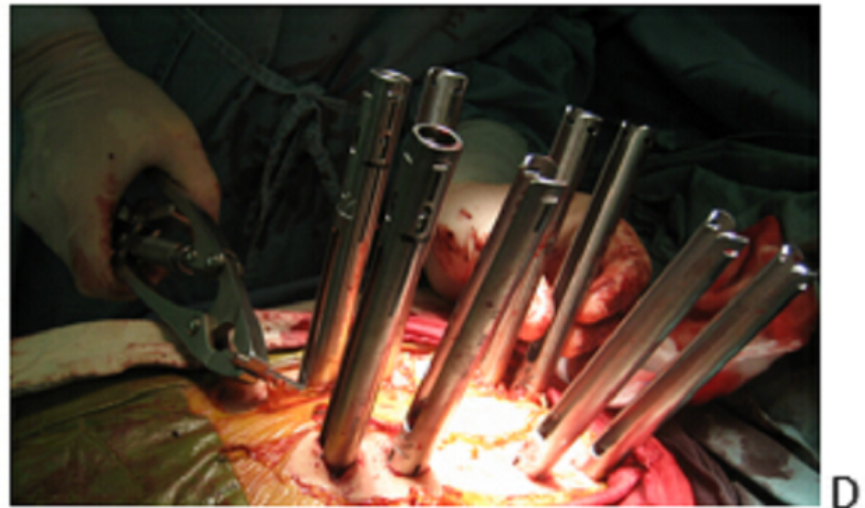

Figure 1: (A) Fluoroscopic image showing insertion of cannulated pedicle screws over the guide wire into the adjacent vertebra below the involved vertebrae after PVP. (B) Photography showing four punctures needles introduced into the adjacent vertebra above the involved vertebrae. (C) Photography showing introduction of cannulated pedicle screws over the guide wire into the vertebral body via the pedicle after the opener and thread tapping were used to enter the pedicle. (D) Photography showing two contoured rods of the appropriate size placed over the pedicle screws through subcutaneous soft tissues and muscles.

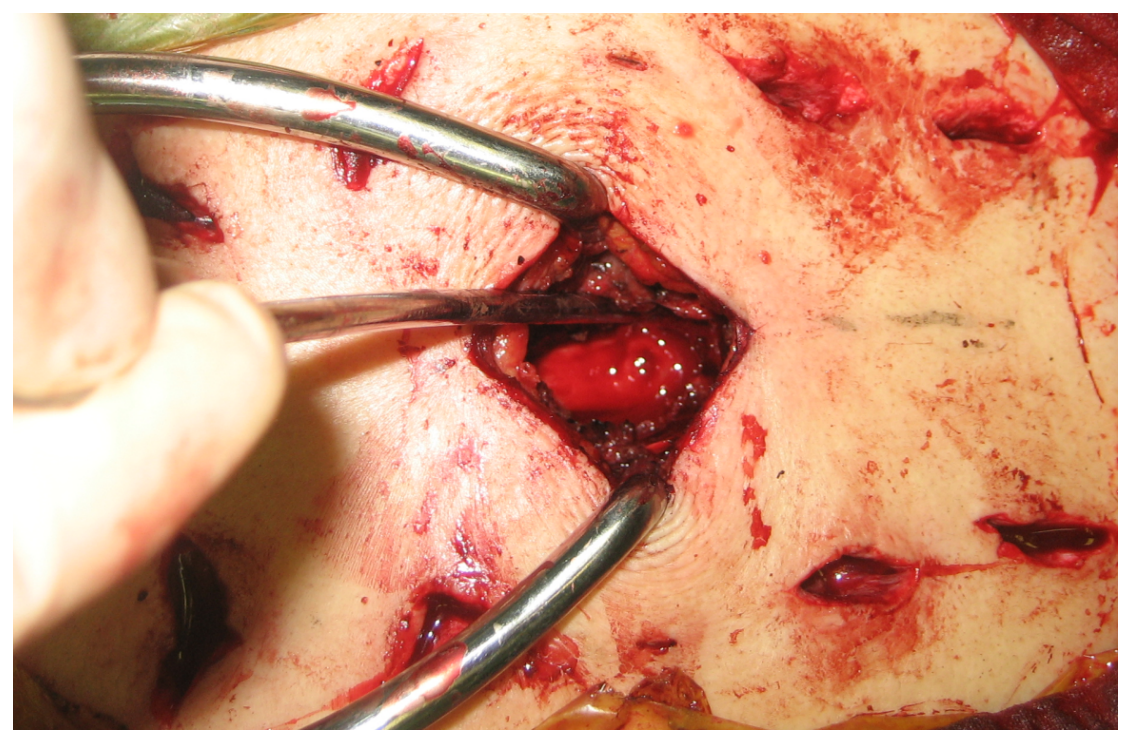

Figure 2: After PPS and PVP, the spinal process and lamina were removed to expose the dural sac involved using the mini midline approach for minimally invasive neurologic decompression. In addition, the pedicle involved and posterior parts of the vertebral body compressing neurologic elements were removed as much as possible for partial tumor resection. 
Citation: Gu YT, Zhang L, Wang YC, Dong J (2019) Minimally Invasive Posterior Decompression and Percutaneous Pedicle Screws Fixation for Thoracic Metastatic Tumor. J Spine 8: 431. doi: 10.4172/2165-7939.1000431

Page 4 of 7

\section{Clinical follow-up}

All of the patients had clinical and X-ray reevaluation during the follow-up after operation. Postoperative complications including wound dehiscence and infection were recorded.

The pain in the previously symptomatic region was measured with visual analog scale pain scores (VAS). A neurologic examination was performed before and after treatment, and the severity of the neurologic deficit was assessed with the ASIA impairment scale [27].

Cobb angle of upper and lower vertebral body involved in internal fixation, central and anterior vertebral body height were measured on the lateral radiographs by the same doctor. The spine was considered stable when no modification in the Cobb angles or in the height of vertebral body was observed during the follow-up.

\section{Statistical analysis}

SPSS software (SPSS Inc., Chicago, IL, USA) was used to perform statistical evaluations. Comparison of preoperative and postoperative VAS, Cobb angle, and the central or anterior vertebral body height was performed using a linear mixed-effects model for multiple comparison procedures. Statistically significant differences were defined at a $95 \%$ confidence level.

\section{Results}

Twenty patients, 11 women and 9 men with a mean age of 56.2 years (range, 29-75 years), were included in this study (Table 2). The mean prognostic score was 7 (range, 6-7 points) according to Tomita scoring system [20]. The mean SINS was 11 (range, 6-14) for spinal instability assessment.

The mean interval between onset of neurologic deficit and surgery was 3.0 days (1-7 days). PPS and PVP, minimally invasive decompression and partial tumor resection was successfully performed for all cases in this study. The duration of operation was $205.3 \pm 10.4 \mathrm{~min}$. There was mean blood loss of $180 \mathrm{ml}(70-550 \mathrm{ml})$. The amount of PMMA injected per vertebral body was $5.9 \pm 1.2 \mathrm{ml}$. The mean stay at hospital was 6 days (4-7 days).

The postoperative X-rays and CT scan images showed that the position of the pedicle screw construct was good (Figures $3 \mathrm{C}-3 \mathrm{G}$ ) and the neurological decompression was complete (Figures $3 \mathrm{H}$ and $3 \mathrm{I}$ ). There is no leakage of polymethylmethacrylate into the spinal canal, and 3 cases of leakage into the intervertebral disc, paraspinal soft tissues or paravertebral vein without clinical consequences were observed.

Clinical outcome: Clinical follow-up was available for 17 patients in this study ranging from 12 to 15 months (mean time, 13.8 months) and other 3 patients died 8-10 months after surgery. There were no perioperative complications such as infection and no death due to complications of the procedure itself.

The pre-operative pain intensity level was 9 (range, 7-10) on the VAS. The VAS score significantly dropped to 3 (range, $2-4)(p<0.001)$ immediately after the operation and to 1 (range, $0-1)(p<0.001)$ at the 1-year follow-up.

In this study 5 patients presented with complete motor paralysis (no motor function, ASIA scale B) and 15 presented with incomplete motor paralysis (ASIA scale C or D). Improvement of paraplegia was observed after surgery in all of these patients. At 3-month follow-up, 3 of 5 patients with complete motor paralysis improved from ASIA scale $\mathrm{B}$ to $\mathrm{D}, 11$ of 15 patients with incomplete motor paralysis from $\mathrm{C}$ or $\mathrm{D}$ to E. Eleven of 17 surviving patients got ASIA scale $\mathrm{E}$ at the 1-year follow-up (Table 2).

Radiological examination: Spine stability was observed in all of surviving patients at the 1-year follow-up, and there was no significant

\begin{tabular}{|c|c|c|c|c|c|c|c|c|}
\hline \multirow{2}{*}{ Patient } & \multirow{2}{*}{ Sex } & \multirow{2}{*}{ Age (years) } & \multirow{2}{*}{ Primary tumor } & \multirow{2}{*}{ Paraplegia Level } & \multirow{2}{*}{ Interval onset-op(d) } & \multicolumn{3}{|c|}{ ASIA } \\
\hline & & & & & & Pre-op & 3-month Follow-up & Latest Follow-up \\
\hline 1 & M & 45 & Liver & T6 & 3 & C & $D$ & $\mathrm{D}$ \\
\hline 2 & $M$ & 57 & Lung & T9 & 7 & $\mathrm{D}$ & $E$ & $E$ \\
\hline 3 & $\mathrm{~F}$ & 48 & Breast & T11 & 6 & $\mathrm{D}$ & $E$ & $E$ \\
\hline 4 & $\mathrm{~F}$ & 56 & Thyroid & T8 & 2 & C & $\mathrm{D}$ & $\mathrm{D}$ \\
\hline 5 & M & 74 & Stomach & T9 & 3 & $\mathrm{D}$ & $E$ & $E$ \\
\hline $6^{*}$ & $\mathrm{~F}$ & 75 & Lung & $\mathrm{T} 12$ & 4 & $D$ & $E$ & \\
\hline 7 & $\mathrm{~F}$ & 49 & Breast & T8 & 1 & C & $E$ & $E$ \\
\hline 8 & $M$ & 67 & Bladder & $\mathrm{T} 7$ & 2 & $B$ & $\mathrm{D}$ & $\mathrm{D}$ \\
\hline 9 & $\mathrm{~F}$ & 57 & Lung & T8 & 4 & $\mathrm{D}$ & $E$ & $E$ \\
\hline $10^{*}$ & $M$ & 45 & Liver & $\mathrm{T} 8$ & 4 & B & $\mathrm{C}$ & \\
\hline 11 & M & 54 & Stomach & $\mathrm{T} 7$ & 1 & C & $E$ & $E$ \\
\hline 12 & $M$ & 39 & Lung & T10 & 1 & B & $D$ & $\mathrm{D}$ \\
\hline 13 & M & 67 & Prostate & T12 & 2 & C & $D$ & $E$ \\
\hline 14 & $\mathrm{~F}$ & 68 & Breast & T6 & 6 & $D$ & $E$ & $E$ \\
\hline 15 & $\mathrm{~F}$ & 29 & Uterus & T8 & 1 & $B$ & $D$ & $\mathrm{D}$ \\
\hline 16 & $\mathrm{~F}$ & 55 & Thyroid & $\mathrm{T} 7$ & 7 & $\mathrm{D}$ & $E$ & $E$ \\
\hline 17 & $\mathrm{~F}$ & 46 & Breast & T12 & 4 & $D$ & $E$ & $E$ \\
\hline 18 & $\mathrm{~F}$ & 59 & Thyroid & $\mathrm{T} 11$ & 2 & C & $D$ & $\mathrm{D}$ \\
\hline 19 & $\mathrm{~F}$ & 68 & Intestine & T9 & 3 & $D$ & $E$ & $E$ \\
\hline $20^{*}$ & $M$ & 66 & Liver & T10 & 3 & $B$ & C & \\
\hline
\end{tabular}

"The patient died of underlying disease more than half one year after surgery. Death was not a result of the procedure.

Table 2: Summary of patient's clinical data. 

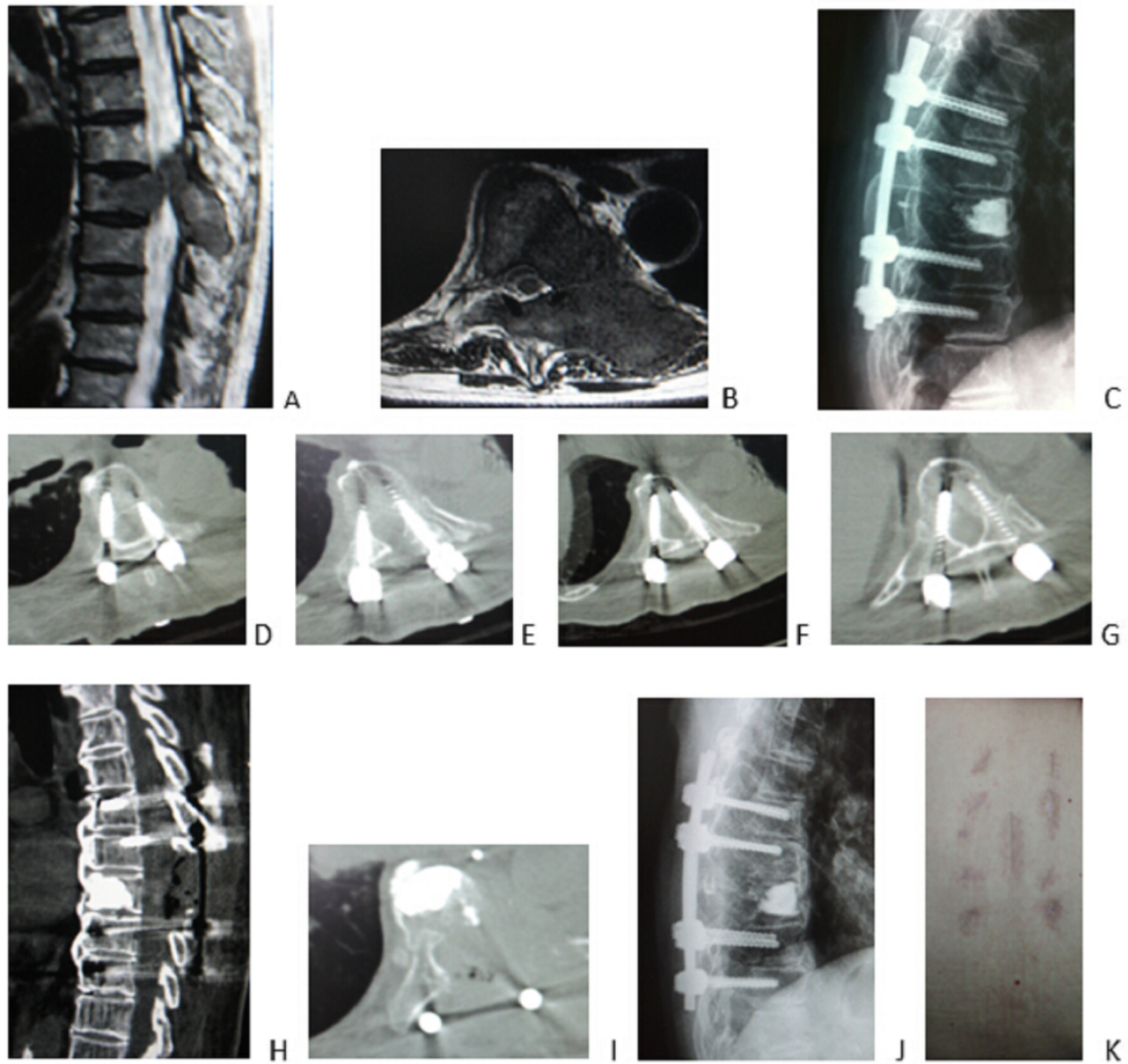

Figure 3: (A) Sagittal and (B) axial MR images show metastasis of T8 from lung cancer with neurologic compression in 57-year-old woman. (C) Lateral X-ray picture, (D-G) CT scan after PPS combined with PVP, minimally invasive decompression and partial tumor resection show good position of the pedicle screw construct and polymethylmethacrylate. There is no leakage of cement into the spinal canal and the neurological decompression is complete on (H) sagittal CT reconstruction and (I) CT scan. No modification in the curvature of the spine and the height of vertebral body is observed on (J) spine X-ray 13 months after surgery. (K) Photography shows minimally invasive results 13 months after surgery (Case 9).

difference in the postoperative Cobb angle, and central or anterior vertebral body height on spine $\mathrm{x}$-rays during the follow-up (Figures 3C-3J).

\section{Discussion}

The strategy for spinal metastases was decided along with the treatment goal set according to the Tomita prognostic scoring system: a prognostic score of 2-3 points suggested a wide or marginal excision such as TES, vertebrectomy, sagittal resection, or resection of the posterior arch for long-term local control; 4-5 points indicated marginal or intralesional excision such as piecemeal excision, eggshell curettage for middle-term local control; 6-7 points justified palliative surgery for short-term palliation; and 8-10 points indicated non-operative supportive care $[20,21,28]$. TES for complete resection of spinal tumors is part of our armamentarium to potentially cure neoplastic disease in selected patients [29]. While TES of primary malignant tumors or aggressive benign tumors for medically fit patients is accepted, there is controversy in spinal metastases that is distant from the primary tumor [30], and there are no data supporting improved quality of life (QOL) and prolonged survival following TES over alternative, less aggressive, surgical and medical treatment paradigms. TES, vertebrectomy, and sagittal resection may remain too aggressive although surgical techniques have been remarkably improved, and the morbidity and mortality rates related to the surgical approach, potential blood loss, extensive dissection and long operative time remain relatively high [2224]. Additionally, piecemeal excision, eggshell curettage and palliative surgery still have the risk of massive blood loss, and there is possibility of biomechanical instability due to the collapse of the involved vertebral body, although screws and rods are used.

Minimally invasive approaches including PPS and PVP dramatically decreases paraspinal musculature iatrogenic injury. Kim and coauthors [31] showed that PPS caused less paraspinal muscle damage than open pedicle screw fixation and had positive effects on trunk muscle. Till now, the techniques of percutaneous osteosythesis are commonly used to treat thoracolumbar fractures [32,33] and as supplemental fixation combined with minimally invasive posterior or anterior lumbar interbody fusion to manage degenerative lumbar diseases $[34,35]$. In this study we designed PVP, minimally invasive decompression and partial tumor resection combined with PPS to treat 20 cases of thoracic vertebral metastases with neurologic compression. Before neurologic decompression and partial tumor resection, two 
rods were placed over the pedicle screws through subcutaneous soft tissues and muscles after insertion of cannulated pedicle screws and PVP in order to decrease the blood loss. If massive blood loss exists during neurologic decompression and partial tumor resection, the procedure can be completed as soon as possible after decompression. In addition, minimally invasive neurologic decompression and partial tumor resection were performed through the mini midline approach, which could decrease aggressiveness and blood loss. Additionally, the cement injected into the vertebral body in PVP could help embolize the rich vessels of the tumor, which may reduce hemorrhage during the removal of posterior part of the vertebra compressing neurologic elements. We found that the morbidity and mortality rates of surgery were minimized, although there was no enough data supporting prolonged survival following the procedure.

All patients got pain improvement in the previously symptomatic region in this study after operation. The postoperative X-rays and CT scan images showed that complete neurologic decompression was achieved through the mini midline approach (Figures $3 \mathrm{H}$ and 3I), which could provide proper angulation for anteromedially neurologic decompression although it is difficult to reconstruct the anterior spine column with cage or other instruments. Improvement of paraplegia was observed after surgery in all of these patients. At 3-month follow-up, 3 of 5 patients with complete paraplegia improved from ASIA scale B to $\mathrm{D}, 11$ of 15 patients with incomplete paraplegia from $\mathrm{C}$ or $\mathrm{D}$ to $\mathrm{E}$. Eleven of 17 surviving patients got ASIA scale $\mathrm{E}$ at the latest followup. The neurological function prognosis had likely relevance to the interval between onset of neurologic deficit and surgery, especially in the patient with complete motor paralysis. Earlier the decompression was performed, better recovery of neurological function was, and the surgery should be undertaken during 2 days after onset of neurologic deficit for the patients with complete motor paralysis. No spine instability was observed in all of surviving patients at the 1-year follow-up. In the cadaveric biomechanical study by Mermelstein and coauthors, it was found that the injection of cement in a burst fracture reduced the load on the pedicle screw construct that was inserted for fracture stabilization [36] and vertebroplasty with cement combined with posterior osteosynthesis might reduce anterior column collapse and hardware failure. Our study confirmed that there was no loosening or fracture of screws and rods in any patient following PPS and PVP after operation.

In our study, inclusion criteria was thoracic metastasis with neurologic compression of one vertebral body lesion and prognostic score of 6-7, which was treated with our minimally invasive strategy replacing traditional palliative care of open surgery. Although the patients had a Tomita score of 6-7 which corresponds to a lifeexpectancy of 6 to 12 months, only 3 patients died before 12 months in this study, which was related to good medical conditions of patients before surgery, less aggressiveness and blood loss during surgery, postoperative improvement of pain and neurological function, and postoperative proper chemotherapy and radiation therapy. The SINS score can also be analyzed as a binary indicator of surgical referral status: 'stable' (0-6) or 'current or possible instability' (7-18) [37]. Surgical consultation is recommended for those patients with a score of $\geq 7$, PVP or internal fixation for possible instability (7-12), internal fixation for current instability (13-18). The patients of this study had 11 (range, 6-14) of SINS score. Although SINS scores of some patients were less than 7 , the neurologic decompression and pedicle screws fixation were needed for their neurologic compression.

\section{Conclusion}

Like all surgical interventions, pedicle screw stabilization has some risks such as nerve injuries. Pedicle screws were implanted in this study using a percutaneous approach under posteroanterior and lateral fluoroscopic control, which was feasible and safe, as supported by the fact that the postoperative CT scan images showed that the screws were all properly positioned in the present series of patients. PVP have some risks including cement leakage into the spinal canal and neurologic deficit. The bone cement was injected into the target vertebral body under constant fluoroscopy during PVP, which must be stopped if the cement got close to the posterior aspect of the vertebral body or leaked into an extraosseous space. All these measures were taken to avoid neurologic damage and guarantee the safety of surgery. However, we also realize the limitation of this minimally invasive technique that the amount of radiation the surgeon and the patient received was more than that in the open surgery. Fluoroscopic projections could be reduced as little as possible in the procedure through simultaneous insertion of 4 or 6 needles for PPS or PVP. The application of navigation system also helps diminish the amount of radiation during surgery.

This study has some limits in that there is no control group. Further studies should be performed to compare this technique with other surgically treated controls. PVP, minimally invasive decompression and partial tumor resection combined with PPS is a good choice of surgical treatment for thoracic metastatic tumors with neurologic compression.

\section{Funding}

- Clinical study on multi-disciplinary diagnosis and treatment of spinal metastases of digestive system tumor supported by scientific research project of Science and Technology Commission of Shanghai Municipality, 17411950302

- Minimally invasive surgical strategy for spinal metastases with neurological compression supported by Project of Shanghai Charity Cancer Research Center, 2017-40

\section{References}

1. Mont'Alverne F, Vallée JN, Cormier E, Guillevin R, Barragan H, et al. (2005) Percutaneous vertebroplasty for metastatic involvement of the axis. AJNR Am J Neuroradiol 26: 1641-1645.

2. Guillevin R, Vallée JN, Lafitte F, Menuel C, Duverneuil NM, et al. (2007) Spine metastasis imaging: Review of the literature. J Neuroradiol 34: 311-321.

3. Constans JP, De Divitiis E, Donzelli R, Spaziante R, Meder JF, et al. (1983) Spinal metastases with neurologic manifestations: Review of 600 cases. J Neurosurg 59:111-118.

4. Harrington KD (1986) Current concepts review: metastatic disease of the spine J Bone Joint Surg Am 68: 1110-1115.

5. Wong DA, Fornasier VL, McNab I (1990) Spinal metastases: The obvious, the occult, and the imposters. Spine 15: 1-3.

6. Ahn H, Mousavi P, Chin L, Roth S, Finkelstein J, et al. (2007) The effect of pre-vertebroplasty tumor ablation using laser-induced thermotherapy on biomechanical stability and cement fill in the metastatic spine. Eur Spine J 16 1171-1178.

7. Whyne CM, Hu SS, Lotz JC (2003) Biomechanically derived guideline equations for burst fracture risk prediction in the metastatically involved spine. J Spinal Disord Tech 16: 180-185.

8. Boland PJ, Lane JM, Sundaresan N (1982) Metastatic disease of the spine. Clin Orthop Relat Res 169: 95-102.

9. DeWald RL, Bridwell KH, Prodromas C, Rodts MF (1985) Reconstructive spina surgery as palliation for metastatic malignancies of the spine. Spine 10: 21-26.

10. Wai EK, Finkelstein JA, Tangente RP, Holden L, Chow E, et al. (2003) Quality of life in surgical treatment of metastatic spine disease. Spine 28: 508-512. 
Citation: Gu YT, Zhang L, Wang YC, Dong J (2019) Minimally Invasive Posterior Decompression and Percutaneous Pedicle Screws Fixation for Thoracic Metastatic Tumor.

11. Cotten A, Dewatre F, Cortet B, Assaker R, Leblond D, et al. (1996) Percutaneous vertebroplasty for osteolytic metastases and myeloma: effects of the percentage of lesion filling and the leakage of methyl methacrylate at clinical follow-up. Radiology 200: 525-530.

12. Weill A, Chiras J, Simon JM, Rose M, Sola-Martinez T, et al. (1996) Spinal metastases: indications for and results of percutaneous injection of acrylic surgical cement. Radiology 199:241-247.

13. Appel NB, Gilula LA (2004) Percutaneous vertebroplasty in patients with spinal canal compromise. AJR Am J Roentgenol 182: 947-951.

14. Shimony JS, Gilula LA, Zeller AJ, Brown DB (2004) Percutaneous vertebroplasty for malignant compression fractures with epidural involvement. Radiology 232: 846-853.

15. Wenger M (2003) Vertebroplasty for metastasis. Med Oncol 20:203-209.

16. Saliou G, Kocheida EM, Lehmann P, Depriester C, Paradot G, et al. (2010) Percutaneous vertebroplasty for pain management in malignant fractures of the spine with epidural involvement. Radiology 254: 882-890.

17. Belkoff SM, Mathis JM, Jasper LE, Deramond H (2001) The biomechanics of vertebroplasty: the effect of cement volume on mechanical behavior. Spine 26 : 1537-1541.

18. Molloy S, Mathis JM, Belkoff SM (2003) The effect of vertebral body percentage fill on mechanical behavior during percutaneous vertebroplasty. Spine 28: 1549-1554.

19. Mathis JM (2002) Vertebroplasty for vertebral fractures with intravertebral clefts. AJNR Am J Neuroradiol 23: 1619-1620.

20. Tomita K, Kawahara N, Kobayashi T, Yoshida A, Murakami H, et al. (2001) Surgical strategy for spinal metastases. Spine 26: 298-306.

21. Boriani S, Weinstein JN, Biagini R (1997) Primary bone tumors of the spine: Terminology and surgical staging. Spine 22: 1036-1044.

22. Kawahara N, Tomita K, Murakami H, Demura S, Yoshioka K, et al. (2010) Total en bloc spondylectomy of the lower lumbar spine: A surgical techniques of combined posterior-anterior approach. Spine 36: 74-82.

23. Fehlings MG, Rabin D (2010) En bloc resection for metastatic spinal tumors: Is it worth it? J Neurosurg Spine 13: 411-413.

24. Murakami H, Kawahara N, Demura S, Kato S, Yoshioka K, et al. (2010) Total en bloc spondylectomy for lung cancer metastasis to the spine. J Neurosurg Spine 13: 414-417
25. Fisher CG, DiPaola CP, Ryken TC, Bilsky MH, Shaffrey Cl, et al. (2010) A nove classification system for spinal instability in neoplastic disease: an evidencebased approach and expert consensus from the Spine Oncology Study Group. Spine 5: E1221-E1229.

26. Weber MH, Burch S, Buckley J, Schmidt MH, Fehlings MG, et al. (2011) Instability and impending instability of the thoracolumbar spine in patients with spinal metastases: a systematic review. Int J Oncol 38: 5-12.

27. American Spinal Injury Association (2003) Reference manual of the international standards for neurological classification of spinal cord injury. Chicago, III: American Spinal Injury Association.s

28. Du ZY, Zang J, Tang XD, Guo W (2010) Experts' agreement on therapy for bone metastases. Orthop surgery 2: 241-253.

29. Jacobs WB, Fehlings, MG (2006) Primary vertebral column tumors. In: Dickman CA, Fehlings MG, Gokaslan ZL, ed. Spinal Cord and Spinal Column Tumors: Principles and Practice. New York: Thieme Medical Publishers 369-386.

30. Bohinski RJ, Rhines LD (2003) Principles and techniques of en bloc vertebrectomy for bone tumors of the thoracolumbar spine: an overview. Neurosurgical Focus 15: E7.

31. Kim DY, Lee SH, Chung SK, Lee HY (2005) Comparison of multifidus muscle atrophy and trunk extension muscle strength: percutaneous versus open pedicle screw fixation. Spine 30: 123-129.

32. Fuentes S, Blondel B, Metellus P, Gaudart J, Adetchessi T, et al. (2010) Percutaneous kyphoplasty and pedicle screw fixation for the management of thoraco-lumbar burst fractures. Eur Spine J 19: 1281-1287.

33. Ni WF, Huang YX, Chi YL, Xu HZ, Lin Y, et al. (2010) Percutaneous pedicle screw fixation for neurologic intact thoracolumbar burst fractures. J Spinal Disord Tech 23: 530-537.

34. Foley K, Gupta SK (2002) Percutaneous pedicle screw fixation of the lumbar spine: Preliminary clinical results. J Neurosurg 97: 7-12.

35. Foley K, Holly LT, Schwender JD (2003) Minimally invasive lumbar fusion Spine 28(suppl): S26-S35.

36. Mermelstein LE, McLain RF, Yerby SA (1998) Reinforcement of thoracolumba burst fractures with calcium phosphate cement: a biomechanical study. Spine 23: 664-670.

37. Fisher CG, Schouten R, Versteeg AL, Boriani S, Varga PP, et al. (2014) Reliability of the spinal instability neoplastic score (SINS) among radiation oncologists: An assessment of instability secondary to spinal metastases. Radiat Oncol 9: 69. 